\title{
ESTRATÉGIAS DE REPRODUÇÃO SOCIAL NO RURAL DA MICRORREGIÃO DE PINHALZINHO (SC)
}

\author{
Lenoir Heisler ${ }^{1}$ \\ Arlene Anélia Renk ${ }^{2}$ \\ Irme Salete Bonamigo ${ }^{3}$
}

\begin{abstract}
RESUMO
No sul do Brasil, em especial no oeste catarinense, o rural vem passando por transformações intensas nos últimos anos. Essas mudanças estão, em grande parte, relacionadas às políticas públicas e à integração das atividades agropecuárias ao mercado global, o que acaba por afetar de modo particular o cotidiano das famílias rurais. O presente artigo analisa as principais estratégias que as famílias do rural na microrregião de Pinhalzinho, oeste da Santa Catarina ${ }^{4}$, utilizam para sua reprodução social. A partir de estudo de caso, por meio de entrevistas com moradores do rural, observações de campo e levantamento em bancos de dados públicos, identifica-se que, entre as principais estratégias de reprodução social acionadas, estão o acesso à educação formal e à previdência social, a constituição de agroindústrias familiares e a abertura de mercados institucionais, a produção alternativa, a entrada no sistema de integração agroindustrial e a pluriatividade. Essas estratégias têm tornado o meio rural pesquisado cada vez mais dinâmico, em muitos casos tido como sinônimo de qualidade de vida.
\end{abstract}

Palavras-chave: campesinato, desenvolvimento rural, reprodução social.

\section{STRATEGIES OF SOCIAL REPRODUCTION IN RURAL AREAS OF THE MICROREGION OF PINHALZINHO (SC)}

\begin{abstract}
In the past few years, in southern Brazil, especially in the west of Santa Catarina, the countryside has undergone intense transformations. These changes are largely related to public policies and the integration of agricultural and livestock activities into the

\footnotetext{
${ }^{1}$ Mestre em Políticas Sociais e Dinâmicas Regionais pela Universidade Comunitária da Região de Chapecó (Unochapecó). Endereço Eletrônico: lenow08@gmail.com

2 Doutora e Mestre em Antropologia pelo Museu Nacional, Universidade Federal do Rio de Janeiro (UERJ). Docente do Programa de Pós-Graduação em Ciências Ambientais da Universidade Comunitária da Região de Chapecó (Unochapecó). Endereço Eletrônico: arlene@unochapeco.edu.br

${ }^{3}$ Doutora em psicologia social pela Universidade do Estado do Rio de Janeiro (UERJ), com pós-doutorado em Psicologia pela Universidade Federal do Rio de Janeiro (UFRJ). Docente do Programa de Pós-Graduação Stricto Sensu em Políticas Sociais e Dinâmicas Regionais da Universidade Comunitária da Região de Chapecó (Unochapecó). Endereço Eletrônico: bonamigo@unochapeco.edu.br

${ }^{4}$ Trata-se de texto elaborado a partir da pesquisa de mestrado apresentada ao Programa de Pós-Graduação em Políticas Sociais e Dinâmicas Regionais da Unochapecó, apoiada pelo programa de bolsas de estudo UNIEDU da Secretaria da Educação do Estado de Santa Catarina.
} 
global market, which affects the daily lives of rural households. This article analyzes the main strategies that rural families in the microregion of Pinhalzinho, west of Santa Catarina, use for their social reproduction. From a case study, through interviews with rural dwellers, field observations and surveys in public databases, it is identified that among the main strategies of social reproduction triggered are access to formal education, social security, constitution of family agroindustries and opening of institutional markets, alternative production, entries in the agroindustrial integration system and pluriactivity. These strategies have made possible to observe a rural environment that is increasingly dynamic and, in many cases, synonymous with quality of life.

Keywords: peasantry, rural development, social reproduction.

\section{INTRODUÇÃO}

No sul do Brasil, em especial no oeste catarinense, o rural vem passando por mudanças significativas nos últimos anos. Essas mudanças podem ser atribuídas, entre outros fatores, ao incentivo governamental através de políticas públicas e programas de desenvolvimento que fomentam a produção, como, por exemplo, o Programa Nacional de Fortalecimento da Agricultura Familiar (PRONAF), a comercialização da produção com o Programa Nacional de Alimentação Escolar (PNAE), o Programa de Aquisição de Alimentos (PAA) e o Sistema de Assistência Técnica e Extensão Rural (ATER). No tema da habitação, também se destaca o Programa Nacional de Habitação Rural (PNHR). Outro aspecto pode estar relacionado à integração da produção agropecuária ao mercado internacional, o que reflete diretamente sobre o preço dos insumos e a renda auferida no meio rural.

Essas transformações no meio rural adentraram as unidades familiares e acabaram por provocar mudanças nas relações sociais e costumes dos seus habitantes - por exemplo, a falta de tempo para realizar os serões ${ }^{5}$ devido à necessidade de atenção contínua à avicultura em sistema de integração. No oeste catarinense, o meio rural da microrregião de Pinhalzinho (SC) - integrada pelos municípios de Pinhalzinho, Saudades, Nova Erechim, Modelo, Serra Alta, Sul Brasil e Bom Jesus do Oeste - foi condicionado por essas situações. A microrregião é interligada pela SC-160 no sentido norte/sul e pela BR-282 no sentido leste/oeste, e lócus de atuação de diversas organizações ${ }^{6}$ sociais. Assim, o município de Pinhalzinho, localizado ao centro da microrregião, constitui-se importante polo comercial e referência cultural.

Os municípios da microrregião possuem um meio rural formado predominantemente por pequenas propriedades que detêm, em média, entre dez e vinte hectares de terra, explorando as atividades com base na mão de obra familiar (IBGE, 2006). A formação da estrutura agrária da microrregião remonta a meados do século $X X$. A vinda de colonos descendentes, isto é, pequenos agricultores em trabalho familiar, em sua grande maioria alemães, italianos e poloneses que migraram do Rio Grande do Sul e buscaram o oeste catarinense como estratégia de reprodução

\footnotetext{
${ }^{5}$ Visitas realizadas entre os moradores de uma localidade próxima, geralmente à noite, para conversar, jogar baralho, cantar, rezar, entre outras atividades, sendo um momento de integração entre as famílias.

${ }^{6}$ Organizações com abrangência na microrregião de Pinhalzinho: Sindicato dos Trabalhadores na Agricultura Familiar de Pinhalzinho e Região, Cooperativa de Crédito Rural com Interação Solidária de Pinhalzinho (Cresol Pinhalzinho), Cooperativa Regional Itaipu (exceto em Nova Erechim), Cooperativa dos Trabalhadores na Agricultura Familiar de Pinhalzinho e Região. Ainda, os municípios constituem uma Região Pastoral (célula organizativa da Diocese de Chapecó que promove interação constante entre seus membros).
} 
social, se deu sob a promessa de terras férteis. A região era habitada originalmente por indígenas e caboclos, o que representou a expropriação destes (WERLANG, 2006). O fechamento da fronteira agrícola, nos anos 1980, influenciou esse contingente populacional.

Embora o meio rural da microrregião seja formado predominantemente por minifúndios, os municípios obtêm um volume considerável do seu valor adicionado ${ }^{7}$ do setor agropecuário, possuindo o rural como importante indutor da economia. Em termos populacionais, o meio rural da microrregião detém $13.717(32,78 \%)$ ante uma população urbana de 28.134 pessoas (67,22\%) (IBGE, 2010). Observa-se que, à exceção do município de Pinhalzinho, todos apresentam patamar superior a $60 \%$ do movimento econômico oriundo diretamente do meio rural, como apresentado na Tabela 1.

Tabela 1 - Valor adicionado da produção agropecuária na microrregião de Pinhalzinho no ano de 2014

\begin{tabular}{|c|c|c|c|}
\hline Município & $\begin{array}{c}\text { Valor } \\
\text { adicionado total } \\
\text { do município }\end{array}$ & $\begin{array}{l}\text { Valor adicionado da } \\
\text { produção } \\
\text { agropecuária/primária }\end{array}$ & $\begin{array}{c}\text { \% Valor } \\
\text { adicionado da } \\
\text { produção } \\
\text { agropecuária/ } \\
\text { primária sobre o } \\
\text { total }\end{array}$ \\
\hline $\begin{array}{r}\text { Bom Jesus do } \\
\text { Oeste }\end{array}$ & 59.132.324,66 & $45.344 .784,49$ & $76,68 \%$ \\
\hline Modelo & $91.687 .888,04$ & $62.390 .343,26$ & $68,04 \%$ \\
\hline Nova Erechim & $175.070 .943,07$ & $130.398 .003,58$ & $74,48 \%$ \\
\hline Pinhalzinho & $609.890 .207,30$ & $147.792 .462,96$ & $24,23 \%$ \\
\hline Saudades & $286.776 .803,18$ & $175.690 .022,32$ & $61,26 \%$ \\
\hline Serra Alta & $78.352 .685,38$ & $52.049 .215,67$ & $66,42 \%$ \\
\hline Sul Brasil & $51.954 .715,81$ & $46.517 .673,99$ & $89,53 \%$ \\
\hline Total & $1.352 .865 .567,44$ & $660.182 .506,27$ & $48,79 \%$ \\
\hline
\end{tabular}

Fonte: SECRETARIA DA FAZENDA DO ESTADO DE SANTA CATARINA (2014).

Para a análise da microrregião de forma consolidada, observamos que 0 valor adicionado da produção agropecuária atinge $48 \%$, conforme a tabela 1 . Este dado aponta forte dependência econômica sobre o setor. Entre as atividades rurais desenvolvidas, estão bovinocultura leiteira e de corte, produção de suínos e aves em sistema de integração e produção de cereais como soja, milho e trigo. $\mathrm{Na}$ microrregião, encontramos também diversas iniciativas de agregação de valor produções caseiras de derivados de leite, cereais, frutas e verduras vendidos em feiras livres - que, por não representarem valores expressivos e por vezes não constarem em registros oficiais, são deixadas de lado pelos agentes públicos e privados dos territórios. Para além da produção, observa-se também na região uma revalorização do rural: o espaço rural deixa de ser apenas produtivo e passa a ser o local de moradia de muitos trabalhadores urbanos e aposentados.

A partir do cenário descrito, o presente artigo propõe-se a analisar as estratégias que as famílias do rural na microrregião de Pinhalzinho (SC), lócus de atuação de um dos pesquisadores, acionam para garantir sua reprodução social,

\footnotetext{
7 "[...] §1으 valor adicionado corresponderá, para cada Município: I - ao valor das mercadorias saídas, acrescido do valor das prestações de serviços, no seu território, deduzido o valor das mercadorias entradas, em cada ano civil." (Lei Complementar n. 63, de 11 de janeiro de 1990, disponível em <http://www.planalto.gov.br/ccivil_03/leis/LCP/Lcp63.htm>).
} 
identificando possibilidades e desafios de cada uma das estratégias. Inicialmente, discute-se o conceito de "reprodução social do campesinato", que fundamenta o texto, descreve-se a metodologia de pesquisa e, em seguida, apresentam-se as principais estratégias de reprodução social adotadas pelos sujeitos da pesquisa de campo: a educação formal e sua influência no rural; a seguridade social; os mercados institucionais, agroindústrias familiares e a produção alternativa; o sistema de integração relacionado à perspectiva dos direitos humanos, sistemas de comunicação e a pluriatividade.

\section{REPRODUÇÃO SOCIAL DO CAMPESINATO}

Uma pausa para tratar da classificação dos sujeitos da pesquisa. Nos cotidianos, os sujeitos identificam-se ora como colonos, isto é, descendentes de imigrantes de europeus que vieram para colonização e assim o foram nominados, ora como agricultores. São associados em Sindicato de Trabalhadores Rurais. Sem dúvida, na Previdência Social estão inseridos como segurados especiais e há uma legislação que os reconhece como agricultores familiares, além disso, há uma literatura farta que os aborda como camponeses. Alguns movimentos sociais, como Movimento dos Trabalhadores Rurais Sem Terra (MST) e Movimento das Mulheres Camponesas (MMC), vinculados à Via Campesina, preferem a terminologia "camponês". Neste texto, utilizaremos a categoria "agricultor familiar" para fazer referência aos sujeitos da realidade empírica e "camponês" quando das referências apresentadas pela literatura.

O camponês pode ser concebido como uma mitificação, sendo que ele "[...] não existe em nenhum sentido imediato e estritamente específico. Em qualquer continente, estado ou região, os assim designados diferem em conteúdo de maneira tão rica quanto o próprio mundo." (SHANIN, 2005, p. 1).

O autor susodito apresenta algumas categorias relacionadas a características pelas quais os camponeses, de modo geral, podem ser representados. Uma primeira é dada pelo trabalho familiar: a família controla os próprios meios de produção, articulando a atividade agrícola com outras, como artesanato ou, ainda, trabalho assalariado por certo período. O planejamento da produção e o cálculo do lucro diferem muito de uma empresa capitalista, o estabelecimento de trocas entre as famílias não segue uma lógica puramente mercadológica. O seguimento e repasse da tradição de modo oral, associados a mapas cognitivos específicos, como a percepção circular do tempo, somados aos padrões específicos de socialização e aprendizado ocupacional do ser camponês dentro da família, são componentes fundamentais do campesinato (SHANIN, 2005).

Woortmann (1990) denomina "campesinidade" ao modo de ser camponês, remetendo à qualidade de ser camponês presente em maior ou menor grau em distintos grupos específicos. De outro modo, pode-se dizer que características camponesas permanecem nas famílias mesmo se estas se submetem a proletarização ou assalariamento, por exemplo.

Portanto, o campesinato aproxima-se de uma classe objeto, como indicado por Bourdieu (1977), haja vista que, dominadas na produção da sua imagem do mundo e, portanto, da sua identidade social, as classes dominadas não falam, elas são faladas pelas classes dominantes que produzem o discurso social a partir de escritores, jornalistas, pintores, entre outros a impor padrões da sua própria percepção. Assim, o camponês é obrigado a construir sua subjetivação sob a objetivação imposta pela classe dominante. 
No Brasil, segundo Wanderley (2014), o campesinato pode assumir faces diversas. Por um lado, pode corresponder às formas tradicionais de agricultura, utilização de escassos recursos produtivos, pouco integrado ao mercado e à vida urbana e frequentemente relacionado ao atraso econômico e social. Nesse sentido, a distinção para com a categoria agricultura familiar encontra-se geralmente, mas não em forma absoluta, no fato de esta ser mais integrada às cidades e principalmente ao mercado (WANDERLEY, 2014).

Diversas foram e continuam sendo as estratégias adotadas pelas famílias de agricultores familiares para garantir a sua reprodução material e simbólica ao longo do tempo. Dentre os fatores que devem merecer atenção, estão as configurações internas, particulares a cada unidade familiar, como o tamanho do lote de terra disponível para exploração, atividades agrícolas desenvolvidas, mão de obra disponível, necessidades individuais dos membros a serem sanadas, costumes e crenças e a relação com o mercado, por exemplo. Relacionada a estes, está também a conjuntura externa, ou seja, aqueles fatores que não estão no domínio da unidade familiar mas interferem diretamente nas estratégias adotadas, como a variação de preços dos insumos e o valor recebido na venda da produção, a disponibilidade de geração de renda não agrícola, a existência de indústrias e/ou mercado consumidor próximo, entre outros (CARNEIRO, 2016).

Dentre os diversos autores que inseriram a temática da reprodução social em suas agendas de pesquisa, pode-se citar Brumer (2004), observando o papel de gênero; Brumer e Spanevello (2008), Spanevello (2008a) e Stropasolas (2004), que se têm dedicado ao estudo da juventude e de estratégias de sucessão nas propriedades rurais no sul do Brasil, cujas teses de doutorado abordaram a problemática; Redin (2015), que realizou estudo juntos aos fumicultores de Arroio do Tigre/RS, estudando as estratégias de reprodução social de que se valem. Respeitadas as particularidades, os agricultores e as diferentes gerações encontram alternativas e arranjos para viabilizar a condição de pequeno agricultor, com estratégias de encaminhamento de filhos e filhas ao "estudo", a profissões no mundo rural ou no urbano, adoção de tecnologias que permitam novas atividades no mundo rural, diversificando-o.

A reprodução social é aqui assumida, portanto, como o conjunto de estratégias adotadas pelas famílias camponesas para garantir sua reprodução material e simbólica ao longo do tempo. Dentre as estratégias, podem-se destacar a definição dos padrões de herança (definição de quem continua na propriedade sucessão), a forma do trabalho dentro e fora da unidade familiar e a relação deste com a tecnologia, o acesso à terra caracterizada por minifúndios, dentre outras. Ainda, a reprodução social não pode ser compreendida ou descrita sem levar em conta a estrutura societária mais geral e o período histórico no qual a família se encontra (SHANIN, 2005). A reprodução social leva em conta também os demais componentes da mesma geração deserdados da propriedade familiar que não permanecerão na propriedade, mas que, de uma forma ou outra, devem ter minimamente assegurada sua sobrevivência. A partir das concepções discutidas é que são apresentadas e discutidas as principais estratégias de reprodução social adotadas pelos sujeitos da pesquisa de campo.

\section{METODOLOGIA}

Em termos metodológicos, esta pesquisa caracteriza-se como um estudo de caso. Segundo Yin (2005), o estudo de caso possibilita descrever mudanças contemporâneas em cenários da vida real por meio de múltiplas fontes de informação. Para melhor conhecer a região em estudo e seus moradores, foi realizada pesquisa 
em bancos de dados públicos do Instituto Brasileiro de Geografia e Estatística (IBGE) e da Secretaria Estadual da Fazenda de Santa Catarina. Também foram realizadas observações, conversas informais e entrevistas semiestruturadas que combinaram perguntas fechadas, para caracterização dos sujeitos e seu contexto histórico, e abertas, nas quais os entrevistados discorreram sobre o tema em questão sem necessariamente prender-se à indagação previamente formulada (MINAYO, 2008). Assim, os entrevistados foram convidados, a partir das provocações/perguntas, a discorrer sobre as atividades desenvolvidas, formas de organização social, entre outras.

A seleção dos moradores do meio rural buscou contemplar todas as faixas etárias e gêneros a partir dos critérios estabelecidos: quatro entrevistados de famílias que não exploram atividade agrícola, mas residem no meio rural (U); quatro entrevistados de família pluriativa $(\mathrm{P})$; quatro entrevistados de famílias que exploram essencialmente as atividades agrícolas $(R)$; dois entrevistados de famílias que trabalham com agroindústria familiar $(F)$; quatro entrevistados de famílias de moradores aposentados $(\mathrm{A})$; dois entrevistados de famílias que trabalham com agroecologia e/ou orgânicos (O).

Ao todo, foram realizadas 20 entrevistas, também conversas informais e observações que foram registradas em diário de campo, isto é, o pesquisador registrou em caderno anotações que considerou importante referentes ao período em que realizou a pesquisa, buscando complementar e situar os discursos apresentados pelos entrevistados. Os entrevistados foram identificados por um conjunto de letras: a primeira corresponde ao grupo de pesquisa; a segunda é aleatória, para controle; seguidas do gênero identificado por uma letra $(F$ ou $M)$ e a geração à qual pertence dentro da unidade familiar, obedecendo a seguinte classificação: considerado jovem $3^{\text {a }}$ geração o entrevistado com até 29 anos; $2^{\underline{a}}$ geração o entrevistado com idade entre 30 e 60 anos; e 1a geração todos com idade acima de 60 anos. Por exemplo: grupo Aposentado, letra de controle, mulher, $1^{\text {a }}$ geração identificado como "AEM1".

Após tabulados, os dados das entrevistas foram agrupados por categorias. Para análise das estratégias de reprodução social, foram identificadas as subcategorias: identidade camponesa, trabalho e tecnologia, educação formal, seguridade social, agroindústrias e produção alternativa, sistema de integração e pluriatividade.

\section{EDUCAÇÃO FORMAL E SUA INFLUÊNCIA NO RURAL}

A busca por estudo ou não também é uma estratégia diretamente relacionada ao padrão sucessório adotado pelos agricultores, como aponta Champagne (1986). O acesso à educação por parte dos moradores rurais em todos os seus níveis chama a atenção nos dados obtidos na pesquisa de campo. Não se tem por objetivo avaliar a qualidade ou as metodologias utilizadas para acesso ou ampliação da oferta do ensino formal, mas apresentar algumas considerações e experiências relatadas pelos sujeitos da pesquisa.

A crescente oferta de ensino público nos níveis básico e médio e a expansão do ensino superior são constituintes de um novo cenário que se desenha na microrregião foco deste estudo. Em muitos casos, por exemplo, o ingresso em um curso superior por parte dos jovens e/ou ainda o apoio moral e financeiro recebido dos pais decorrem da impossibilidade da divisão ou exploração do lote de terra disponível. Assim, o acesso ao ensino revela-se como uma espécie de herança antecipada, equivalendo, por exemplo, a conseguir adquirir uma área de terra, para tirar o seu sustento e melhorar a qualidade de vida. 
A associação entre baixo nível educacional e o trabalho nas atividades agrícolas é um mecanismo acionado pelos moradores do espaço rural na microrregião. Essa ideia parte do princípio de que, para o trabalho físico na agricultura, não é necessário concluir os estudos formais; é necessário aprender a desempenhar as atividades no dia a dia. Apesar de ainda ser frequentemente acionada, tal concepção apresenta sinais de mudança: as observações de campo indicam a necessidade de conhecimento formal para melhor administrar as atividades agrícolas.

O acesso à educação de nível básico e médio por parte dos filhos e filhas das famílias agricultoras acontece em todas as localidades do meio rural, com a disponibilização de transporte e ensino público gratuito. O ensino básico também está presente em outras gerações. Com a descentralização das turmas do Centro de Educação de Jovens e Adultos (CEJA) nas comunidades do interior, muitas pessoas tiveram e estão tendo acesso ao Ensino Básico e Médio. Exemplo desta descentralização é encontrado no município de Pinhalzinho, que possuía no momento da pesquisa três turmas do CEJA funcionando em localidades rurais. A possibilidade de buscar novos conhecimentos provoca uma melhora significativa na autoestima das/os estudantes, na sua grande maioria, mulheres que não tiveram a oportunidade de concluir seus estudos no tempo oportuno.

$O$ acesso ao Ensino Superior por parte dos filhos e filhas dos agricultores era algo distante, haja vistas a escassez de oferta de cursos em locais próximos e a falta de recursos financeiros para manter-se e pagar os estudos. No último período, especialmente na última década, os moradores da microrregião tiveram uma gama de oportunidades advindas da ampliação da oferta de cursos e melhora na situação econômica das famílias, que puderam vislumbrar na educação uma oportunidade para a vida. Para o entrevistado $\mathrm{PKH}^{\mathrm{a}}$, os jovens já saem do Ensino Médio com a expectativa de frequentar um curso superior:

\begin{abstract}
"A Unoesc veio para cá, a federal [UFFS] veio para cá, a própria Uninter. Então ele sai do Rodrigues Alves [escola estadual] já com o pensamento de ir fazer, estudar um curso superior. Não importa se é aqui, se é em outra região, mas de uma ou outra maneira vão." (PKH2ª , 20/09/2016).
\end{abstract}

Não são raros os casos em que os filhos e filhas das agricultores e agricultoras familiares puderam ter acesso ao Ensino Superior, seja na modalidade de tecnólogo, seja na de bacharelado ou licenciatura. Outro dado que chama a atenção é o de que alguns desses filhos e filhas, após a conclusão, permanecem residindo no meio rural, inclusive fixando residência. Um exemplo está na propriedade do entrevistado PMH3áa: após a conclusão do curso de Agronomia, o jovem voltou a residir no meio rural, auxiliando na gestão da propriedade, embora também possua um trabalho urbano.

\footnotetext{
“É... Hoje, pensando em acesso à educação eu sou formado numa universidade federal, e isso com certeza assim se não fosse essa oportunidade, essa possibilidade de acessar a universidade federal provavelmente não teria me formado. [...] E hoje posso ter o meu trabalho e ajudar nas decisões da propriedade." (PMH3ª, $03 / 09 / 2016)$.
}

Outro caso é o da família URH3a , em que os dois jovens $(30,26)$, com curso superior completo, decidiram retornar ao meio rural, conciliando as atividades urbanas com as atividades agrícolas da propriedade. 
A interação dos moradores do meio rural com o meio urbano e os estudos, por exemplo, acabam por ressignificar a forma como os moradores do meio rural se veem. Embora não exercendo diretamente a atividade agrícola na propriedade, a terminologia "agricultor familiar" é apresentada pelo jovem entrevistado:

\begin{abstract}
"É... Hoje, assim, eu, a partir também do que a universidade me proporciona a questão de estudo, eu, assim, eu tenho muita clareza que eu sou agricultor familiar, mas com certeza assim se pega minha família, meu pai talvez ele denomina a questão de agricultor, mas muito fortemente vai ficar a questão do colono, é essa a visão geral que se tem, a questão do povo da roça, o colono, inclusive assim, muitas vezes, a questão de preconceito por trás, inclusive." (PMH2a $2^{\mathrm{a}}$, 03/09/2016).
\end{abstract}

Quando tratamos do acesso ao ensino superior, logo se toma a universidade como espaço de formação profissional, portanto, de pessoas jovens. Na microrregião, foi possível identificar a existência de uma turma da Universidade da Terceira Idade ${ }^{8}$, que tem por objetivo "contribuir para a promoção da qualidade de vida e do desenvolvimento cultural e social dos participantes envolvidos nas atividades" (UNOESC, 2017). O requisito para ingresso é saber ler e escrever. Durante o trabalho de campo, conversamos com um casal de agricultores aposentados que frequentam a Universidade da Terceira Idade: "Demora para chegar a quarta-feira. O estudo é um máximo. Por que sem educação você não é ninguém. Quando você escuta, você aprende." (AGH1'a, 20/09/2016).

A valorização atribuída à possibilidade de estudo indiferentemente da faixa etária evidenciou-se em muitas das entrevistas. O acesso à educação formal por parte dos moradores rurais, ao mesmo tempo que é por eles avaliada como negativa por forçar a saída dos jovens do campo, apresenta sinais de mudança em sua concepção: ela passa a receber um caráter positivo, assemelhando-se, em muitos casos, a uma conquista. Se, em outros tempos, a formação de novas famílias passava pela aquisição de uma área de terra e alguns bens para o início das atividades agrícolas, as observações de campo permitem assinalar que ela se converte em muitos casos a garantir que os filhos e filhas concluam o Ensino Básico e, sempre que possível, avancem para o ensino superior.

\title{
5. PREVIDÊNCIA SOCIAL E AGRICULTURA FAMILIAR
}

Outra estratégia de reprodução social adotada pelos sujeitos da pesquisa de campo foi a previdência social, uma forma de proteção social. Segundo Yazbek (2014), não são encontradas na história humana sociedades que não tenham desenvolvido sistemas de proteção aos seus membros mais vulneráveis, quer sejam esses sistemas mais rústicos e não tão especializados, como a família, quer apresentem altos níveis de sofisticação e especialização. Nesse sentido, é pertinente realizar uma contextualização sobre o surgimento das políticas sociais, convergindo em muitos países para sistemas de bem-estar social, denominados também de Welfare

\footnotetext{
${ }^{8}$ A Universidade da Terceira Idade, ou UNITI, é um projeto desenvolvido pela Universidade do Oeste de Santa Catarina (UNOESC) que tem por objetivo "[...] ser um espaço que visa formar o idoso de forma integral, proporcionando-Ihes uma melhor qualidade de vida. Incentivar a busca de uma reciclagem pessoal e o entendimento, pelo idoso, quanto ao seu papel social na contemporaneidade. Desenvolver potencialidades e propiciar vivências de novas experiências. Promover ações que garantam o bem estar biopsicossocial dos idosos." (UNOESC, 2017).
} 
State. Conforme Fiori (1997), cabe destacar que os sistemas de proteção social ao longo da história são diversos, conforme as características de cada período.

Constituem-se como sistema de proteção social

"[...] as formas - às vezes mais ou menos institucionalizadas que as sociedades constituem para proteger parte ou o conjunto de seus membros. Tais sistemas decorrem de certas vicissitudes da vida natural ou social, tais como a velhice, a doença, o infortúnio e as privações." (DI GIOVANNI, 1998, p. 10).

Para Sposati (2009), o sentido de "proteção" supõe, antes de tudo, um caráter preservacionista e de defesa da vida, dos direitos humanos e sociais e da dignidade humana. Assumida pelo Estado brasileiro e reconhecida pela sociedade como função legítima, a proteção social se institucionaliza e toma formas concretas através de políticas de caráter social (YAZBEK, 2010). A política social pública permite aos cidadãos acessar recursos, bens e serviços sociais necessários sob múltiplos aspectos e dimensões da vida: social, econômico, cultural, político, entre outros.

Segundo Yazbek (2010 p. 4), é importante destacar que o avanço das questões sociais não ocorre por acaso, mas possui um caráter histórico e político que se dá por meio das lutas por direitos sociais, da formação de consensos políticos, de sucessivas e intermináveis pactuações que, considerando as diferenças no interior das sociedades, buscam incessantemente responder a pelo menos três questões: quem será protegido? Como será protegido? Quanto de proteção?

A inclusão dos trabalhadores rurais no regime geral da previdência é um marco histórico e provocou mudanças no meio rural. Segundo Luiz (2017, não paginado):

"[...] a conquista da previdência rural para o campesinato faz parte do reconhecimento da realidade socioeconômica que vive a mulher e o homem do campo, a sua própria formação histórica - principalmente em relação à terra, largamente concentrada nas mãos dos latifundiários. Adiciona-se a ausência do Estado na implementação de políticas para as populações camponesas."

Entre as mudanças ocorridas após o acesso, podemos citar o empoderamento das mulheres, que, subalternizadas em muitas situações, não possuíam acesso ao dinheiro ou sua administração e, a partir da aposentadoria, passam a ter o seu dinheiro - dinheiro este que auxilia em tratamentos de saúde, na compra de remédios e na satisfação de outros desejos pessoais e simbólicos dos aposentados.

\begin{abstract}
"Sem esse dinheirinho que vem todo mês não sei como eu iria viver. Porque a gente já não pode mais trabalhar muito no pesado, e com esse dinheirinho, mesmo que não seja muita coisa, posso comprar uns agradinhos para os netinhos." (ATM1" 15/10/2016).
\end{abstract}

Mesmo entre os homens, a possibilidade de uma renda fixa mensal representada pelo benefício permite a melhora da qualidade de vida com segurança. Os relatos dos entrevistados aposentados destacam a participação nos chamados grupos de idosos. Estes grupos se constituem como espaços de convivência em que são cultivados alguns costumes como a reza católica, os jogos de baralho, as danças de salão, entre outros. Decorrente dessa organização, acontecem as festas de 
idosos ${ }^{9}$, nas quais se reúnem os grupos de idosos em um salão de festas para confraternizar. Nesse sentido, a seguridade social apresenta-se como elemento importante à medida que possibilita a participação e interação dos aposentados na comunidade local, o que outrora não seria possível, haja vistas as condições de vida das famílias.

\section{AGROINDÚSTRIAS FAMILIARES E MERCADOS INSTITUCIONAIS}

Industrializar e agregar renda à produção da propriedade familiar tem sido uma das estratégias utilizadas para a manutenção das famílias no meio rural, conforme já fora abordado por Dorigon e Renk (2014) em estudo na área de abrangência da Agência Regional de Desenvolvimento de Maravilha (SC).

A abertura dos mercados institucionais, através do Programa de Aquisição de Alimentos (PAA) e do Programa Nacional de Alimentação Escolar (PNAE) para a aquisição direta de alimentos, é apresentada pelas famílias que exploram a agroindustrialização de base familiar na região como um dos fatores para o seu surgimento, como apresentado no relato:

"Isso faz oito anos. Era aqui na comunidade, tinha uma reunião. Daí um que trabalha na prefeitura disse assim: 'Eu precisava alguém que entrasse para fazer as coisas para a merenda [escolar]'. E daí eu disse: 'Mas como funciona, como que é, e tudo?' 'Passa lá uma hora que eu vou te explicar bem certo'. Daí como eu tenho problema no braço e não posso me esforçar muito, disse: 'vou lá ver como funciona'. Daí ganhamos uma ajuda da prefeitura de máquina e coisa." (FBM2a $\left.{ }^{\mathrm{a}}, 03 / 10 / 2016\right)$.

surgimento das agroindústrias familiares na microrregião de Pinhalzinho (SC) possui muitas semelhanças. A exclusão do sistema tradicional de produção por meio da não identificação ou não possibilidade de produção de commodities forçou as famílias que desejavam se manter na pequena propriedade a encontrar outros caminhos. Foi desse modo que uma das famílias pesquisadas iniciou sua trajetória na agregação de valor na propriedade, transformando-se, posteriormente, em um empreendimento que atualmente emprega a mão de obra de todo o grupo familiar, constituído de oito pessoas:

"A gente foi migrando, conforme hoje em dia quem tem pequena propriedade que não tem aviário, chiqueirão, essas coisas aí, se tu não vai fazendo outras coisas, senão tu fecha. Foi achado uma alternativa para sobreviver as famílias na propriedade." (FPM3 $\left.{ }^{-}, 23 / 09 / 2016\right)$.

"Mas foi por aí que começou, o pessoal aceitou o nosso produto, começou a procurar mais e aí nós fomos devagarzinho aumentando, e legalizando depois e estamos hoje, acho, com oito anos legalizado os nossos produtos com rótulo e tal." (FBH2 $\left.{ }^{\mathrm{a}}, 23 / 09 / 2016\right)$.

\footnotetext{
${ }^{9}$ Os municípios da região possuem uma organização denominada grupos de idosos, auto-organizados, apoiados pelo CRAS, que viabiliza o encontro das pessoas idosas com o intuito de confraternizar. Esses encontros ocorrem, em sua maioria, duas vezes ao mês. Os grupos geralmente são organizados por proximidade geográfica, utilizando-se da organização comunitária da igreja católica, nas próprias comunidades. Mensalmente, ocorrem as festas de idosos, itinerantes, nas quais os grupos se visitam e confraternizam (Nota de Diário, 26/12/2016).
} 
Um dos entrevistados relata que a opção pela agroindustrialização deu-se em função da possibilidade de redução do uso e contato com agrotóxicos e trabalho ao abrigo do sol:

"[...] quando vê, nós sentimos que isso seria uma maneira de nós nos livrarmos, praticamente, não $100 \%$, mas $80 \%$ do agrotóxico que nós usávamos, por que tinha que usar para produzir estas outras coisas e com a agroindústria trabalhava um pouco mais na sombra, um pouco mais tranquilo." (FBH3ª, $23 / 09 / 2016)$.

Em relação ao trabalho desenvolvido nas agroindústrias, os entrevistados destacam que é mais fácil, não sendo tão penoso como em outros tempos, embora também exija esforço e dedicação.

"Não é que não é puxado, uma padaria, o sofrimento às vezes as três horas da madrugada levantar para fazer pão também não

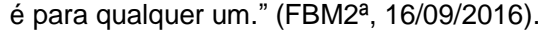

Entre as principais atividades desenvolvidas a partir da agroindustrialização familiar, encontram-se a revalorização dos produtos nominados como coloniais, derivados, especialmente, de carnes, como os embutidos; do leite, especialmente os queijos; da cana-de-açúcar, como o melado; de frutas, com as conservas, sucos; e da farinha de trigo, como as bolachas, pães e cucas.

$\mathrm{Na}$ pesquisa de campo, foi possível constatar que a atividade da agroindústria familiar possui um aspecto de gênero. Na sua grande maioria, essas iniciativas são geridas por mulheres; diferentemente do que ocorre com as demais atividades rurais, são elas que possuem o domínio da produção e gestão do negócio. Este aspecto pode estar relacionado a uma questão cultural: para os homens, a tarefa de garantir a continuidade da família por meio do trabalho braçal, em atividades que objetivam auferir renda monetária; já às mulheres, a responsabilidade pelas atividades de manutenção, como o plantio de hortaliças, legumes, batatinha, cebola, alho, fabricação de pães, bolachas, cucas e outros derivados de cereais, produção de ovos e frangos, denominadas "miudezas". As observações de campo apontam que a maioria dessas agroindústrias desenvolveu-se a partir das atividades desenvolvidas pelas mulheres para suprir a alimentação da família, ou seja, sem geração de renda. As mudanças ocorridas na economia local, especialmente a melhora do poder aquisitivo da população, somada à revalorização dos ditos "produtos coloniais" (DORIGON; RENK, 2014), oportunizaram a expansão de uma produção, ainda que artesanal, para fora dos limites da unidade familiar, transformando-se em instrumento de autonomia para muitas mulheres.

A busca de uma legislação sanitária e fiscal compatível com as pequenas agroindústrias familiares é apontada como um dos desafios para esta estratégia de reprodução social. O estímulo à produção orgânica e agroecológica, a oferta de assistência técnica e extensão rural adequada e de qualidade são alguns dos desafios no campo de alternativas ao modelo tradicional de produção.

\section{SISTEMA DE INTEGRAÇÃO AGROINDUSTRIAL}

Identificou-se, também, como estratégia de reprodução social adotada pelos sujeitos da pesquisa de campo o sistema de integração agroindustrial, que, no Brasil, tem seu advento nas décadas de 1970 e 1980, com a abertura comercial e entrada no mercado mundial (BELATO, 1985; ESPÍNDOLA, 1999; DALLA COSTA, 1993). Assim, o sistema de integração encontra nas regiões com predominância de 
pequenas propriedades um campo propício a sua implantação, oportunizando a reprodução social dos agricultores, por meio de fontes de renda "mais viáveis - fixas certas" comparativamente às atividades que dependem fundamentalmente das condições climáticas. Dentre as principais cadeias que se inserem no sistema de integração, estão as de aves, suínos e fumo.

O sistema de integração é caracterizado pela celebração de um contrato entre a indústria integradora (empresa ou cooperativa) e o produtor, denominado "integrado". Nesse contrato, estão dispostas as obrigações de cada parte na parceria, cabendo ao produtor integrado disponibilizar a infraestrutura para implantação da atividade, como galpões, área de terra, máquinas e equipamentos, e principalmente a mão de obra necessária para o desenvolvimento das atividades. O integrado obrigase, por adesão, a acatar as orientações técnicas, adquirir os insumos e efetuar a venda da produção à indústria integradora. Compete à integradora o fornecimento de insumos, a prestação de assistência técnica e a aquisição do produto final segundo critérios preestabelecidos não passíveis de questionamento pelo integrado. Segundo Nogueira e Jesus (2013), a ideia básica do sistema de integração é a de que as agroindústrias forneçam toda a tecnologia aos pequenos produtores.

Nas atividades pecuárias (suínos e aves), o tempo dedicado à produção é praticamente integral, com jornadas que podem passar de 14 horas diárias. $\mathrm{Na}$ atividade agrícola (fumo), a jornada de trabalho não difere, somando-se a exposição ao sol e os agrotóxicos por longos períodos. Desse modo, a participação em reuniões, nas celebrações comunitárias, nas atividades de lazer e a visitação aos vizinhos e parentes, conhecidas também como "serões", são abdicadas em função da dedicação necessária à atividade de integração (BONAMIGO; RENK; DORIGON; 2015).

$\mathrm{O}$ direito ao recebimento de uma remuneração justa pelo trabalho realizado também é desrespeitado no sistema de integração. Na pesquisa de campo, foi possível identificar que o preço pago por um suíno de aproximadamente $90 \mathrm{Kg}$ produzido no sistema de integração varia de $R \$ 15,00$ a $R \$ 29,00$; o valor recebido por um avicultor varia entre $R \$ 0,45$ e $R \$ 0,65$ por frango entregue à integradora. Esses dois exemplos mostram a baixa remuneração recebida pelos produtores no sistema de integração. O valor a ser pago pelo produto entregue é definido pela integradora com base em seus indicadores, como a taxa de conversão alimentar, a mortalidade, adequação das estruturas produtivas e o ganho de peso diário (MENDES; PATRÍCIO, 2004), cabendo a esta também a análise e conceituação desses indicadores, tendo em conta a variação do mercado. Estudos apontam que a remuneração recebida pelos integrados é praticamente insuficiente para o pagamento de empréstimos decorrentes da implantação da atividade de integração e conseguinte manutenção familiar (BELATO, 1985; ESPÍNDOLA, 1999; DALLA COSTA, 1993). Este aspecto também foi identificado com os participantes das pesquisa:

"Passou-se lá seus 10,15 anos tu paga o investimento e você tem o capital e você ainda consegue trabalhar. Mas aí já vem a tal da manutenção, às vezes a estrutura já não serve mais, enfim, então a forma que as empresas têm de amarrar o produtor, de tal forma que ele é obrigado a trabalhar por migalhas. Então essas ressalvas, tem que refletir um pouco diferente no sistema de integração." (ARH3ạ , 13/10/2016).

O endividamento dos integrados para com a integradora ou com agentes financeiros em virtude do investimento inicial e das constantes exigências por melhorias nas estruturas produtivas, por parte do mercado e das integradoras, é um fator que condiciona muitas famílias a se comprometerem a produzir para a empresa 
integradora numa condição análoga à servidão por dívidas. Nesse sentido, os agentes técnicos cumprem um papel estratégico para as integradoras, visto que são os responsáveis diretos pela pressão exercida sobre os integrados. Esta prática é repudiada internacionalmente por meio da Convenção sobre Trabalho Forçado da Organização Internacional do Trabalho n. 29, ratificada pelo Brasil (SORJ; WILKINSON, 2008).

$\mathrm{Na}$ pesquisa de campo, verificou-se que as unidades familiares que possuem implantado algum modelo de integração agroindustrial dificilmente dependem apenas dessa atividade, como observado na entrevista:

\begin{abstract}
"A gente se preparou com os porcos e com as vacas para seguir essas atividades e se melhorar em algum sentido ali, até ampliar. [...] E o porco não está tão bom hoje, o porco hoje se tu vais ver bem, ele paga o salário daquele que cuida. Mas daí a gente faz a seguinte conta, o lucro nosso, o maior lucro nosso é o adubo que tem. Então por esse motivo que a vaca de leite é um grande negócio para a propriedade. A gente não compra adubo, nada. E o porco também dá dinheiro, não é que ele não dá. Ele ajuda, ele paga o investimento e sobra um pouco." (RKH2a 18/10/2016).
\end{abstract}

$\mathrm{Na}$ fala, encontramos outro aspecto interessante relacionado à interação das atividades produtivas: para além da viabilidade, embora pequena, o entrevistado cita o uso dos dejetos (esterco) para uso como fonte de nutrientes às pastagens destinadas à exploração pecuária com gado de leite. criticidade:

O sistema de integração também é avaliado por alguns entrevistados com

\begin{abstract}
"A integração ela sempre é uma alternativa, né? Se tu vai analisar quem tem integração, a contrapartida que o agricultor tem que dar é muito grande em vista do rendimento que ela gera. [...] Porém, chuva ou sol é um rendimento que vem." (RRH1a, 18/10/2016).
\end{abstract}

Relacionado a essa alternativa e garantia de renda, está o papel do sistema de integração no meio rural da microrregião e seu impacto nas relações sociais. Para um dos entrevistados, os trabalhos no sistema de integração, embora tenham viabilizado as propriedades, especialmente as com pequenas áreas de terra, com não mais do que 15 hectares, tiraram a liberdade de escolha dos agricultores em relação ao seu tempo: "Às vezes em pedaço pequeno de terra muitos conseguiram se
viabilizar no sistema de integração. Então ele é bom, não é de
todo ruim, tem os dois lados. Eu acho que é bom até certo
ponto... Mas a integração tirou bastante a liberdade do próprio
colono. Eu acho que evolui com isso [a produção] em grande
quantidade, mas até certo ponto tirou bastante a liberdade do
colono. Tem que se deixar mandar se não, não dá certo."
(AJH2ª , 20/09/2016).

O cerceamento da liberdade ora apontado tem seus impactos sentidos nas relações comunitárias dos habitantes. Assim, o tempo disponível para participar de reuniões, cultos e lazer é reduzido. Um dos sujeitos da pesquisa apresenta o sistema de integração 
como um modelo que necessita de reformulações, uma vez que os agricultores estariam envelhecendo:

"[...] o modelo de integração, ao que tudo indica, ele vai se remodelar. Essas cooperativas velhas possivelmente elas vão teimar um pouquinho, por que está muito bom. A agricultura está envelhecendo, esse pessoal que investiu, que entrou de cabeça nesse sistema de integração estão aos poucos parando." (RKH2a ${ }^{\mathrm{a}}$, 20/09/2016).

Em meio a este cenário, o sistema de integração constitui-se importante fator para manutenção e continuidade de muitas famílias no meio rural. Torna-se difícil imaginar o cenário rural e urbano da microrregião sem esse elemento importante que, apesar das críticas dirigidas, possibilita a geração de inúmeros empregos diretos e indiretos. Caberia, talvez, como apontado por um dos participantes da pesquisa, uma discussão, entre o poder público, empresas integradoras e produtores, acerca das responsabilidades e remuneração final recebida pelos produtores integrados.

\section{PLURIATIVIDADE}

O consórcio de atividades de geração de renda não agrícola, ou seja, não estritamente da exploração agropecuária no meio rural, é um fenômeno presente na realidade brasileira e uma estratégia de reprodução social rural dos agricultores pesquisados. Para Carneiro (2016), esse fenômeno denominado "pluriatividade" manifesta-se especialmente naquelas situações em que a integração da agricultura familiar aos mercados alcança um novo estágio ou se dá por uma via distinta, o mercado de trabalho. Para Schneider (2007, p. 4):

"[...] a pluriatividade refere-se à um fenômeno que pressupõem a combinação de duas ou mais atividades, sendo uma delas a agricultura, em uma mesma unidade de produção por indivíduos que pertencem a um grupo doméstico [...], que compartilha entre si um mesmo espaço de moradia e trabalho (não necessariamente em um mesmo alojamento ou habitação) e se identificam como uma família."

Schneider (2003) sugere algumas características presentes nas mudanças da ocupação do espaço rural e do crescimento da pluriatividade. A primeira, relacionada com a modernização técnica e produtiva da agricultura, em que a maior disponibilidade de tecnologias que usam cada vez menos força de trabalho gera uma subocupação e torna-se fator que estimula os membros das famílias com domicílio rural a buscar ocupação em atividades não agrícolas. Uma segunda, ligada à terceirização das atividades agrícolas, especialmente aquelas na qual o agricultor contrata terceiros para serviços eventuais como plantio, manejo e colheita, liberando a mão de obra antes ocupada nos trabalhos manuais. A terceira refere-se à queda nas rendas agrícolas, decorrentes da entrada da agricultura nos padrões de concorrência mundial, que implica aumento de custos decorrentes em grande medida da dependência maior de insumos industriais, que nem sempre se traduzem em aumento de produção. Um quarto aspecto, ligado às mudanças nos mercados de trabalho: empresas mudam suas plantas industriais para regiões rurais de alta densidade populacional buscando redução do custo na força de trabalho, e proporcionam acesso ao mercado de trabalho urbano aos agricultores. $O$ quinto aspecto trata do crescente reconhecimento da importância que a agricultura familiar 
tem no meio rural: ela passou a ser a principal forma social presente nos espaços rurais dos países capitalistas mais desenvolvidos, sendo a pluriatividade percebida como uma das estratégias fundamentais de reprodução da agricultura familiar e adaptação às transformações macroestruturais na agricultura.

Carneiro (2016) destaca que a combinação de atividades agrícolas e não agrícolas tanto pode ser um recurso do qual a família faz uso para garantir a reprodução social do grupo ou do coletivo que lhe corresponde, como também pode representar uma estratégia individual, dos membros que constituem a unidade doméstica. Corroborando a afirmação da autora, ao buscar rendas não agrícolas, especialmente o assalariamento, as famílias pesquisadas buscam empregar a mão de obra dos seus membros após o seu horário de trabalho e nos finais de semana dentro da propriedade.

Assim, quando tu tens um tempo tu ainda consegues dar uma mãozinha em casa. Então tu ajudas a carregar os porcos. Às vezes na negociação tu ficas em casa no final de semana. Dá pra negociar. (PHF3, 20/10/2016).

Nas observações de campo, pôde-se perceber que a relação entre trabalho e penosidade no meio rural diminui; porém, as falas dos entrevistados revelam uma nova situação: as horas dedicadas à execução das atividades ampliaram-se.

A visão que eu hoje tenho, tipo assim, não olhando o meu caso aqui em casa, mas pelo que a gente vê e conversa enfim, hoje o campo ele te dá uma renda maior, porém ele te dá mais hora de serviço, não é um trabalho mais tão penoso como era uma vez, é um trabalho que é bom você estar no campo, porém ele te dá, no meu caso a gente percebe dá mais serviço. Não é só 8 horas, tem que contar 10, 12 horas tu faz brincando. (AHB2, 20/10/2016).

Esta observação está relacionada a outro fator responsável pela busca de renda externa à propriedade. Explorar alguma atividade agrícola, leite, frangos e suínos pressupõe manter-se vigilante 24 horas por dia. Ter liberdade igual ao trabalhador urbano, não necessitando retornar à propriedade para realizar alguma atividade nos finais de semana e feriados, por exemplo, motiva especialmente os jovens a buscar rendas externas à propriedade, mesmo residindo com os pais.

A busca por oportunidades de trabalho e renda fora da propriedade apresenta-se como uma importante alternativa para as famílias do meio rural na microrregião de Pinhalzinho (SC), como pode ser observado no relato:

\footnotetext{
Primeira razão puramente econômica [...] tanto o fato de busca um trabalho fora, uma por agregar também a questão de renda e também atrelada a questão de formação acadêmica. [...] pra se manter hoje na cidade o custo de vida é altíssimo, e isso então, a gente consegue de certa forma trabalha com um custo bem mais baixo residindo hoje no meio rural ainda, [...] na questão de calma, tranquilidade de se tá em casa no dia a dia com a família. (PRH3, 18/09/2016).
}

O relato traz elementos importantes para compreender a pluriatividade no meio rural: ela está relacionada com a questão de renda e possibilidade de estudo. $O$ relato aponta, ainda, para uma positivação, revalorização do meio rural como sinônimo de qualidade de vida. A relação familiar aparecer como outro ponto importante: pode 
ser observado que as decisões e estratégias são pensadas coletivamente pelos membros da família.

A possibilidade de emprego assalariado, seja no meio urbano ou nas proximidades do local de moradia, também é fator importante a ser considerado. Os entrevistados apontam a proximidade com o centro urbano como ponto favorável à busca de renda externa à propriedade. O destaque à qualidade das vias de acesso é de suma importância para possibilitar a continuidade da estratégia familiar.

[...] hoje a gente tem essa oportunidade de trabalhar fora e morar em casa, a questão de logística facilita. Nós estarmos morando perto da cidade, então isso se torna viável. Por que eu hoje aqui por exemplo até o meu serviço dá $5 \mathrm{~km}$. Depende onde que eu vou ter que, se eu for alugar uma casa, aquilo que tinha possibilidade de pagar é lá em cima no final da cidade. Talvez a distância seria a mesma, talvez uns metros a menos. Então não é viável, não se torna viável. (PHF3, 18/10/2016).

Para um dos entrevistados, a busca dos filhos e filhas por alternativas de renda fora da propriedade também esteve associada à dimensão da área de terra da família:

A terra é pequena então nós temos que criar alternativas. Ou você arrenda ou você compra... [...] então se fica quase num limite de produção, ao menos pra vaca tá no limite. A não ser que você invista e otimize a produção. (AHR2, 23/09/2016).

O entrevistado relata a possibilidade de financiamentos com recursos subsidiados pelo Programa Nacional de Fortalecimento da Agricultura Familiar (PRONAF), porém destaca que as linhas de crédito são muito recentes.

Mas assim, na época pelo menos quando eu sai não se tinha essa perspectiva. Nem as possibilidades. Isso chegou depois do Mais Alimentos (programa governamental de subsídio) que criou mais perspectivas, mais alternativas para pequena propriedade. (AHR2, 23/09/2016).

Uma das principais motivações para busca de renda não agrícola é a garantia por um valor fixo ao final de certo período de trabalho; no entanto, percebe-se, em relação aos filhos e filhas, uma independência na administração dos recursos recebidos por este - os recursos são utilizados, na sua grande maioria, para satisfação das necessidades individuais dos membros da família. A compreensão da ajuda nas despesas familiares ocorre com a realização de tarefas em momentos oportunos.

Cada um trabalha e gasta o que trabalha. Só o pai e a mãe mesmo na atividade deles. O que é produzido na propriedade. Mas nós não, nós (ele e o irmão) temos as nossas coisas. (PHR3, 27/09/2016).

Eu tenho a minha renda. Administro o meu dinheiro. Ajudo meus pais de vez em quando, mas o que eu ganho é meu. Estou guardando para o futuro. Tenho uma independência financeira. (PHF3, 27/09/2016).

Em outro estudo realizado pelos pesquisadores em uma localidade distante $7 \mathrm{~km}$ de um centro urbano, constatou-se que, das 62 famílias residentes, 32 possuem membros que buscam fontes de renda fora das atividades agrícolas, ou seja, são 
pluriativas. Em 10 famílias, a renda das atividades não agrícolas é maior do que as agrícolas. Esses dados necessitam ainda de análises mais aprofundadas e comparativas, por exemplo, com comunidades rurais mais distantes dos centros urbanos, porém chamam a atenção para uma mudança do cenário rural dos centros urbanos dos municípios da microrregião.

\section{CONSIDERAÇÕES FINAIS}

A microrregião de Pinhalzinho (SC) deste estudo apresenta um predominante caráter rural. O que, por vezes, não é visível é que esse rural tem se modificado ao longo do tempo, com a constante interação dos seus moradores com outros espaços e através do acesso a uma gama cada vez maior de recursos tecnológicos, seja na área da comunicação, produção ou bens de consumos. Há uma perceptível redução de distância entre os modos de vida dos meios rural e urbano em termos de acesso aos meios de comunicação e bens de consumo.

O crescente acesso ao ensino formal, seja das gerações mais novas, sejam as oportunidades para adultos e idosos, provocou mudanças no modo de viver das famílias rurais. É possível perceber que o acesso ao conhecimento formal obtido pelas famílias de agricultores provoca uma melhor gestão dos recursos financeiros e, por consequência, do desenvolvimento das atividades rurais. Isso possibilita que o trabalhador do campo amplie o horizonte de suas análises, tenha acesso e busque informações sobre os processos produtivos, tornando-se mais independente frente ao mercado. $\mathrm{O}$ acesso ao conhecimento está relacionado, ainda, ao desenvolvimento de diversas atividades diferentes da produção agropecuária no meio rural.

No entanto, segundo os entrevistados na pesquisa de campo, o acesso ao ensino formal traz consigo alguns riscos, especialmente quando o assunto é sucessão na propriedade rural. Para eles, o atual currículo escolar fica distante da realidade rural, estando voltado ao meio urbano, desde o material didático à formação do professor. Até mesmo nas instituições que ofertam uma dinâmica voltada ao meio rural, a formação tende a ser para o trabalho urbano. No mesmo debate, estão a centralização das escolas no meio urbano e o fechamento das escolas no meio rural ocorrido no final da década de 1990, por decisão do governo estadual de Santa Catarina. Essas dificuldades apontadas pelos agricultores são desafios que precisam ser enfrentados.

Surgindo como uma alternativa às famílias rurais, a agroindustrialização de base familiar tem-se mostrado ferramenta importante para manutenção das famílias no meio rural. Estimulada por um mercado crescente de valorização dos produtos de origem cultural (italiana, alemã e cabocla), denominados "produtos coloniais", bem como por estímulo governamental por meio dos programas de alimentação escolar e Programa de Aquisição de Alimentos (PAA), a agroindustrialização de base familiar vai-se consolidando. Diferencia-se da grande agroindústria pelo porte (micro) e relação próxima entre a família que produz e o consumidor final, tendo o produto, em sua grande maioria, um caráter artesanal. Entre os principais desafios para o desenvolvimento desta atividade, encontram-se a legislação e a carga tributária, que, segundo os entrevistados, é igual à grande agroindústria, embora seu caráter seja bem diferenciado. Este aspecto tem grande influência na viabilidade dos pequenos empreendimentos familiares.

Por outro lado, encontramos na microrregião uma cooperativa que procura organizar e apoiar as famílias que estão e/ou que possuam interesse na agroindustrialização de base familiar. Esta cooperativa está filiada a uma cooperativa central e procura, através do cooperativismo, organizar, legalizar e possibilitar a comercialização dos produtos das agroindústrias de base familiar, além de ser uma 
instância representativa e de luta das pequenas agroindústrias. A agroindustrialização familiar de produtos originários das unidades familiares, associada à abertura dos mercados institucionais, vem viabilizando muitas famílias. Estes empreendimentos ainda contam com uma importante característica de gênero: administração e gestão são realizadas, na grande maioria, por mulheres.

$\mathrm{Na}$ pesquisa realizada, a pluriatividade interligada em muitos casos com o acesso ao ensino formal chamou a atenção. A busca crescente e as oportunidades para obter rendas não agrícolas no meio rural da microrregião têm-se transformado em importante estratégia acionada pelos moradores. Grande parte destas oportunidades surge no setor de serviços, devido, em grande parte, ao poder aquisitivo dos moradores da microrregião. Outro aspecto relacionado ao crescimento da pluriatividade é a interação entre os moradores do meio rural e urbano, caracterizado pelos laços de parentesco (filhos e filhas, irmãos e irmãs, pais e mães, tios e tias, sobrinhos e sobrinhas), somados ao acesso a um número maior de bens para consumo por parte das unidades familiares rurais, especialmente veículos, que acaba por diminuir a distância física $(20 \mathrm{~km})$, perpassando também os modos de vida das famílias.

A busca pela moradia no meio rural da microrregião, especialmente nas localidades mais próximas aos centros urbanos, tem-se intensificado. Embora o trabalho seja desenvolvido fora da propriedade, a moradia no meio rural funciona como uma espécie de refúgio e busca por qualidade de vida, segundo os entrevistados. Entre os desafios apontados, encontram-se as condições das vias de acesso, situação que já apresentara melhora em relação a períodos anteriores. Devese ressaltar, porém, a inexistência de políticas públicas que possam dar conta dessa nova realidade do meio rural.

Enquadrados como segurados especiais, os agricultores e agricultoras percebem no benefício recebido do INSS uma possibilidade de diminuição na jornada de trabalho diária, haja vista também a diminuição das condições físicas para realização das atividades. Nos municípios da microrregião, são muitas as famílias que possuem no benefício mensal a sua maior e segura fonte de renda. No trabalho de campo, observou-se que receber o benefício após uma vida de trabalho é correlacionado a uma conquista, especialmente pelas mulheres, que, ao longo da história, em sua grande maioria, não participaram ou tiveram acesso aos recursos financeiros da família. Além de contribuir na melhora da autoestima dos agricultores, a aposentadoria rural contribui de forma decisiva na economia local.

$\mathrm{Na}$ atualidade, está em discussão no Brasil a reforma da previdência social, o que acabaria por alterar também as condições para a aposentadoria rural. Este cenário coloca em alerta uma grande parcela da população rural possivelmente atingida pela mudança na legislação. Dentre as propostas de mudanças, estão a elevação da idade mínima para a aposentadoria rural das mulheres de 55 para 60 e dos homens de 60 para 65 anos. Está em estudo, também, a forma de contribuição dos segurados, que passaria a ser obrigatória.

A integração agroindustrial continua a ter papel fundamental na geração de renda das famílias rurais, sendo responsável por ocupar mão de obra e prover insumos para as demais atividades rurais. Entre os limites apontados na pesquisa de campo, estão a jornada de trabalho, que pode chegar a 24 horas em alguns períodos, a baixa remuneração e a necessidade de um alto grau de investimento, às vezes constante, para continuidade das atividades. De outro lado, tal integração possibilita a obtenção de renda fixa a cada período, conforme o ciclo de cada atividade, minimizando o fator climático, e não necessita de grandes áreas de terra.

Diferentemente de projeções de esvaziamento do meio rural, percebe-se na microrregião um movimento de valorização do espaço rural, seja para produção e 
geração de renda, seja como espaço para moradia e obtenção de maior qualidade de vida. Para tanto, compreender as estratégias que as famílias moradoras do rural acionam para garantir sua reprodução social é elemento importante com vistas ao aprimoramento das políticas públicas e atuação das organizações sociais.

\section{REFERÊNCIAS}

ALMEIDA, L.R. da S. Pierre Bourdieu: a transformação social no contexto de "a reprodução". Inter-ação, Goiânia, v.1, n.30, p.139-155, jan. 2005. Disponível em: http://www.revistas.ufg.br/index.php/interacao/article/view/1291/1343. Acesso em: 25 jul. 2015.

BELATO, D. Os camponeses integrados. 1985. 443f. Dissertação (Mestrado em História) - Programa Pós-graduação em História, Universidade Estadual de Campinas.

BONAMIGO, I.S.; RENK, A.; DORIGON, C. Direitos humanos, direito dos animais e consumo de carne. In: CONGRESSO BRASILEIRO DE SOCIOLOGIA, 17., 2015, Porto Alegre. Anais... Porto Alegre: Sociedade Brasileira de Sociologia, 2015. p.1-20.

BOURDIEU, P. Une classe objet. Actes de la recherche em sciences sociales, Paris, v. 17-18, p. 2-5, 1977.

BRUMER, A. Gênero e agricultura: a situação da mulher na agricultura do Rio Grande do Sul. Estudos Feministas, Florianópolis, v.12, n. 1, p.205-227, jan./abr. 2004.

BRUMER, A.; SPANEVELLO, R.M. Gênero e reprodução na agricultura familiar. Revista Nera, Presidente Prudente, v. 11, n.12, p. 6-17, jan./jun. 2008.

CARNEIRO, M.J. Pluriatividade no campo: o caso francês. Revista Brasileira de Ciências Sociais, São Paulo, v.11, n.32, p.89-105, 1996. Disponível em: http://www.anpocs.org.br/portal/publicacoes/rbcs_00_32/rbcs32_06.htm. Acesso em: 10 mai. 2015.

CHAMPAGNE, P. Ampliação do espaço social e crise da identidade camponesa. Cahier d'Economie et Sociologie Rurales, n. 3, p.73-89,1986. [Tradução do texto "Elargissement de l'espace social et crise de l'identidade paysanne"]

CHAYANOV, A.V. La organizacion de unidad económica campesina. Buenos Aires: Nueva Vision, 1974.

DALLA COSTA, A.J. O grupo Sadia e a produção integrada: o lugar do agricultor no complexo agroindustrial. 1993. 265f. Dissertação (Mestrado em História) Mestrado em História do Brasil, Universidade Federal do Paraná.

DI GIOVANNI, G. Sistema de proteção social: uma introdução conceitual. In: OLIVEIRA, M.A. de (Org.). Reforma do Estado e política de emprego. Campinas: IE/UNICAMP, 1998. p.9-29.

DORIGON, C.; RENK, A. Juventude rural e reconversão produtiva rumo a produtos de qualidade diferenciada. In: RENK, A.; DORIGON, C. (Org.). Juventude rural, cultura e mudança social. Chapecó: Argos, 2014. p. 35-76. 
ESPÍNDOLA, J.C. As agroindústrias no oeste catarinense: o caso Sadia. Chapecó: Grifos, 1999.

INSTITUTO BRASILEIRO DE GEOGRAFIA E ESTATÍSTICA. Censo Agropecuário 2006. Rio de Janeiro: IBGE, 2006. Disponível em: http://www.ibge.gov.br/home/ estatística/economia/ agropecuária/censoagro/2006. Acesso em: 10 jun. 2015.

Censo Demográfico 2010. Rio de Janeiro: IBGE, 2010. Disponível em: https://ww2.ibge.gov.br/home/estatistica/populacao/censo2010/default.shtm. Acesso em: 16 jun. 2015.

FIORI, J.L. Estado de Bem-Estar Social: padrões e crises. Physis: Revista Saúde Coletiva, Rio de Janeiro, v.2, n.7, p.129-147, nov. 1997.

LUIZ, C. O desmonte da Previdência e as consequências para o campesinato brasileiro. CEERT, 17 mar. 2017. Disponível em: http://www.ceert.org.br/noticias/ mercado-de-trabalho-comercio-servicos/16225/o-desmonte-da-previdencia-e-asconsequencias-para-o-campesinato-brasileiro. Acesso em: 15 abr. 2017.

MENDES, A.A.; PATRÍCIO, I.S. Controles, registros e avaliação do desempenho de frangos de corte. In: MENDES, A.A.; NÄÄS, I.A.; MACARI, M. Produção de frangos de corte. Campinas: FACTA, 2004. p.328.

MINAYO, M.C. de S. Análise do material qualitativo: análise de conteúdo. In: MINAYO, M.C. de S. O desafio do conhecimento: pesquisa qualitativa em saúde. 11.ed. São Paulo: Hucitec, 2008. p.303-311.

NOGUEIRA, C.M.I; JESUS, E. de. A pequena produção avícola familiar e o Sistema de Integração no oeste catarinense: "uma prisão de portas abertas". Caderno CRH, Salvador, v.26, n.67, jan./abr. 2013.

REDIN, E. Família rural e produção de tabaco: estratégias de reprodução social em Arroios do Tigre/RS. 2015. 307f. Tese (Doutorado em Extensão Rural) - Programa de Pós-Graduação em Extensão Rural, Universidade Federal de Santa Maria.

SECRETARIA DA FAZENDA DO ESTADO DE SANTA CATARINA. Distribuição do valor adicionado por município. Florianópolis, 2014. Disponível em: http://www.sef.sc.gov.br/transparencia/ relatorio/21. Acesso em: 17 mar. 2016.

SCHNEIDER, S. A importância da pluriatividade para as políticas públicas no Brasil. Revista de Política Agrícola, Brasília, a.16, n.3, p.15-34, jul. 2007. Disponível em: http://www.ufrgs.br/pgdr/arquivos/409.pdf. Acesso em: 20 out. 2015.

2003.

A pluriatividade na agricultura familiar. Porto Alegre: Editora UFRGS,

SHANIN, T. A definição de camponês: conceituações e desconceituações - o velho e o novo em uma discussão marxista. Nera, Presidente Prudente, a.8, n.7, p.1-21, jul./dez. $2005 . \quad$ Disponível em: http://www.reformaagrariaemdados.org.br/sites/default/files/1456-4239-1-PB.PDF. Acesso em: 2 fev. 2016. 
SORJ, B.; WILKINSON, J. Processos sociais e formas de produção na agricultura brasileira. In: SORJ, B.; ALMEIDA, M.H.T. de (Org.). Sociedade política no Brasil pós-61. Rio de Janeiro: Centro Edelstein de Pesquisas Sociais, 2008. p.245-278.

SPANEVELLO, R.M. A dinâmica sucessória na agricultura familiar. 2008. 221f. Tese (Doutorado em Desenvolvimento Rural) - Programa de Pós-Graduação em Desenvolvimento Rural, Universidade Federal do Rio Grande do Sul.

SPOSATI, A. Modelo brasileiro de proteção social não contributiva: concepções fundantes. In: UNESCO. Concepção e gestão da proteção social não contributiva no Brasil. Brasília: MDS/UNESCO, 2009.

STROPASOLAS, V.L. O valor (do) casamento na agricultura familiar. Estudos Feministas, Florianópolis, v.12, n.1, p.253-267, jan./abr. 2004.

UNOESC. UNITI, UMIC e UMIX

s.d. Disponível em: https://www.unoesc.edu.br/portal/uniti-umic. Acesso em: 01 ago. 2017.

WANDERLEY, $M$. de N.B. O campesinato brasileiro: uma história de resistência. Revista de Economia e Sociologia Rural, Brasília, v.52, supl.1, p.25-44, 2014. Disponível em: http://www.scielo.br/pdf/ resr/v52s1/a02v52s1.pdf. Acesso em: 02 jan. 2017.

WERLANG, A. Disputas e ocupação do espaço no oeste catarinense. Chapecó: Argos, 2006.

WOORTMANN, K. "Com parente não se neguceia": o campesinato como ordem moral. Anuário Antropológico, Brasília, v.87, p.11-73, 1990.

YAZBEK, M.C. Sistemas de proteção social, intersetorialidade e integração de políticas sociais. In: MONNERAT, G.L.; ALMEIDA, N.L.T. de; SOUZA, R.G. de (Org.). A intersetorialidade na agenda das políticas sociais. Campinas: Papel Social, 2014. p.77-104.

Sistema de proteção social brasileiro: modelo, dilemas e desafios. 2010. Disponível em: http://www.mds.gov.br/saladeimprensa/eventos/assistencia-social/ seminario-internacional-bpc/sobre-o-

evento/apresentacoes/arquivos/MariaCarmelitaYazbek-Protecao Social.pdf/view. Acesso em: 20 jul. 2015.

YIN, R. Estudo de caso: planejamento e método. Porto Alegre: Bookman, 2005. 